Electroencephalography and Clinical Neurophysiology

Elsevier Publıshıng Company, Amsterdam - Printed in The Netherlands

\title{
VISUALLY EVOKED RESPONSES IN MIGRAINE ${ }^{1}$
}

\author{
E. T Richey, M.D. ${ }^{2}$, K. A. KoOI, M.D. And R. W Waggoner, M D \\ Laboratory of Electroencephalography, Neuropsychiatric Institute, University of Michtgan Medical Center, \\ Ann Arbor, Mich. (US A.)
}

(Accepted for publication January 28, 1966)

\section{INTRODUCTION}

Particularly relevant to the present study is a report by Golla and Winter (1959) in which it was concluded that patients with migraine responded to a wider range of stımulus frequencies than control subjects A curve of frequency of stimulation versus "abundance" of response was called the migraine or " $\mathrm{H}$ " type of curve. Smyth and Winter (1964) found the H curve in patients with other conditions besides migraine.

The purpose of this paper was to investigate visually evoked responses to single flashes in patıents with migraine using averaging technique, a method that gives detailed information about individual components of the response It was hypothesized that one or more components of the response might be exaggerated.

\section{METHODOLOGY}

Forty-six normal subjects (30 females, 16 males) and 50 patients with migraıne ( 32 females, 18 males) were studied The two samples were comparable in respect to age (averages of 29 and 30 years, respectively) Control subjects were in good health and without neurological illness. The patients were examined when free of headache. In each case, the diagnosis was made according to criteria from a recent classification of headaches (1962). Each patient had recurrent episodes of headache, usually unilateral in onset, often associated with anorexia, and usually with nausea and vomiting. Some type of aura was present in 21 cases The final diagnosis of migraine was verified by the Neurology Service.

The procedure was the same for all subjects and patients Technical detals have been described before (Kooi and Bagchı 1964a, b). Three

${ }^{1}$ Supported in part by U.S P.H.S. Grant NB 02560.

${ }^{2}$ Lt Col., USAF, MC. 8-channel computer runs were carried out. During the first run, data were obtained from frontal, central, occipital, and temporal areas of the two sides. The reference was joined-ears. Occipital electrodes were placed $3 \mathrm{~cm}$ above and $3 \mathrm{~cm}$ lateral to the inion Data from the other two computer runs were used to assess artifacts and substantiate the initial observations Pupil sizes were measured 1 mmediately before and after the three computer runs Correlations between the means from two sets of measurements were 078 for the patients, 087 for the control population.

Individual components of the response from occipital and central regions were analyzed The left-sided values were used for statistical analysis (see Kool et al. 1965) The vertex sharp wave, a surface negative deflection (CV) and the preceding surface positive wave (CIV) were evaluated from the central response Measurement criterı and ranges for latencies and amplitudes of the occipital and central components are based on previous studies by Kool and Bagchı (1964a, b) as well as some additional data obtaned from the present experıment. If eye blınk artıfact extended into the central regions, vertex sharp wave data were not used

Amplitude orders were tabulated for major components of the occipital response in the migraine and control groups. Waves having the greatest, second greatest and third greatest amplitudes, in both negative and positive directıons, were identified and their latencies plotted (Fig. $1, A$ and $B$ )

\section{RESULTS}

The great majority of resting records ( 39 out of 50) were either entirely normal or showed borderlıne non-specific findings. Six records were mildly abnormal with scattered, non-focal slow waves, three showed distinct focal slow wave 


\section{A. CONTROL}
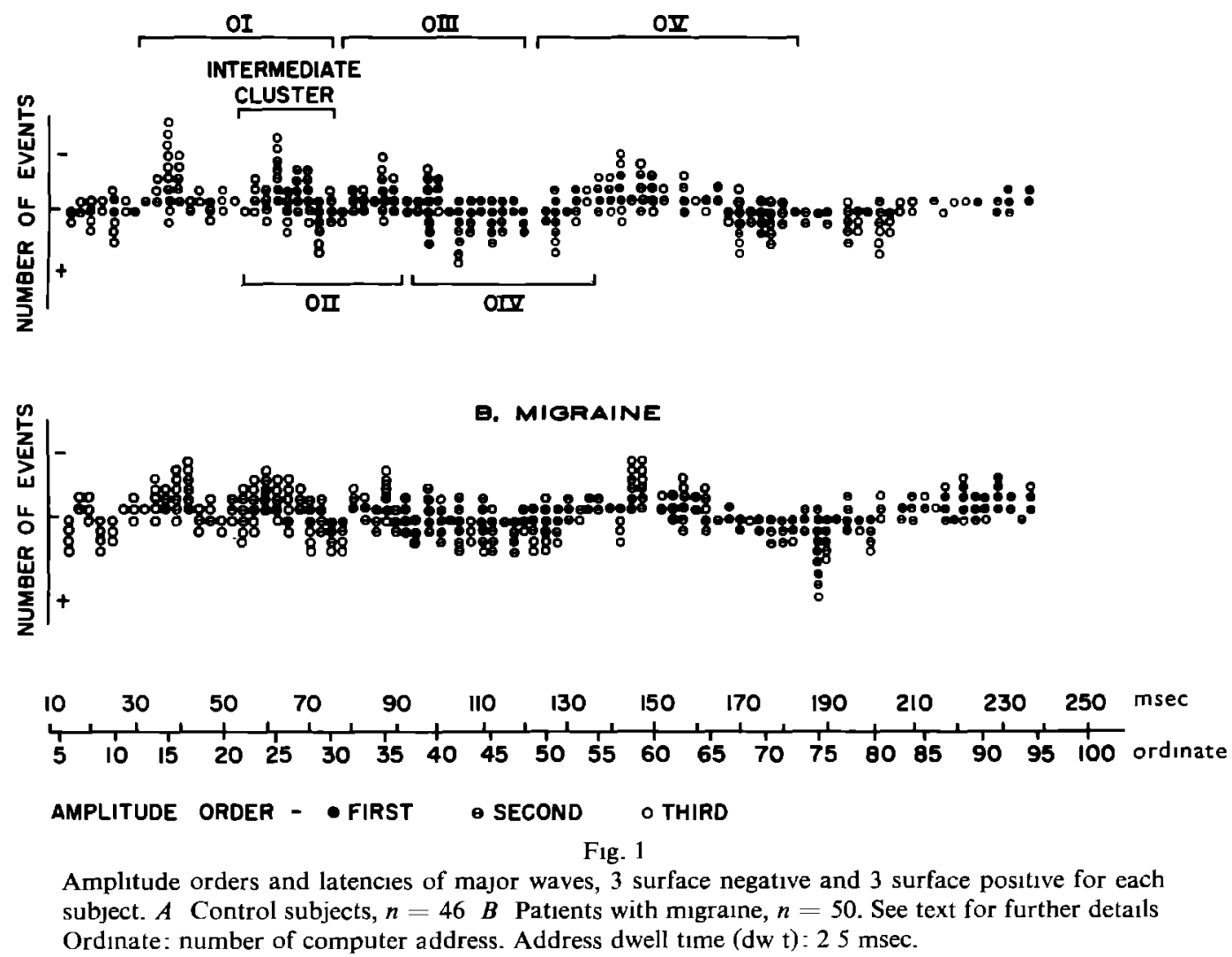

abnormalties, two being in the left temporal region and one in the left posterior temporooccipital area Two subjects had paroxysmal records (spike and wave discharges in the resting EEG and photoconvulsive responses to photic stımulation). Neither had a history of seizures.

Fig $1, A$ and $B$ reveals no gross differences between the control and patient groups in the general form of the visually evoked response. The first major wave of the occipital response (OI) is surface negative and culmınates withın a latency range of 30-75 msec. Inspection of peak latencies of responses within this general latency range suggests that it may be subdivided into two subclusters, an early cluster with a range of 30$525 \mathrm{msec}$ and a later cluster ("intermediate" component) of $55-75 \mathrm{msec}$ (see also Fig. 2, $A$ and $B$ ). Latency characteristics of later deflectıons have been already described (Kooi and Bagchi 1964a, b).
Latencies and amplitudes of the vertex sharp wave were not significantly different for the migraine and control groups (Table I).

Average latencies of occipital components are

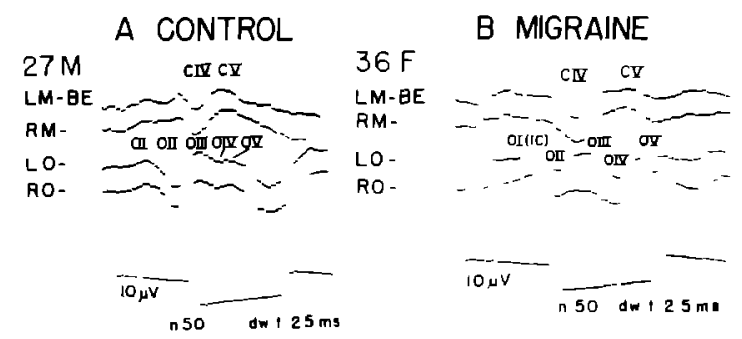

Fig 2

$A$ Typical responses in central and occipital regions of a normal subject $B$. Example of responses in central and occipital regions of a patient with migraine selected to illustrate the intermedrate component The degree of leftright amplitude asymmetry of OIII is an unusual but not necessarily abnormal findıng Analysis perıod $250 \mathrm{msec}$ $M \cdot$ motor, $O$ occipital, $L$ left, $R$ right

Electroenceph. clin. Neurophystol , 1966, 21:23-27 
TABLE I

Vertex sharp wave data for migraine and control groups

\begin{tabular}{|c|c|c|c|c|c|c|c|c|}
\hline & \multicolumn{4}{|c|}{ Migraine $(n=50)$} & \multicolumn{4}{|c|}{ Control $(n=46)$} \\
\hline & \multicolumn{2}{|c|}{ Latency (msec) } & \multicolumn{2}{|c|}{ Amplitude $(\mu \mathrm{V})$} & \multicolumn{2}{|c|}{ Latency (msec) } & \multicolumn{2}{|c|}{ Amplitude $(\mu \mathrm{V})$} \\
\hline & Males & Females & Males & Females & Males & Females & Males & Females \\
\hline $\mathbf{N}$ & 15 & 29 & 15 & 29 & 12 & 24 & 12 & 24 \\
\hline CIV & 102.8 & 102.0 & 5.1 & 5.3 & 978 & 1003 & 4.7 & 40 \\
\hline $\mathrm{CV}$ & 1363 & 1335 & 9.1 & 106 & 134.5 & 1313 & 105 & 107 \\
\hline
\end{tabular}

TABLE II

Analysis of latency averages for occipital components

\begin{tabular}{|c|c|c|c|c|c|c|}
\hline & OI & $\begin{array}{l}\text { Intermediate } \\
\text { cluster }\end{array}$ & OII & OIII & OIV & OV \\
\hline \multicolumn{7}{|c|}{$A$ Combined $(M$ and $F)$} \\
\hline Migraine & $41.3 *(50)^{* *}$ & $62.0(26)$ & $71.5(48)$ & $920(48)$ & $113.3(48)$ & $143.5(46)$ \\
\hline Control & $41.0 \quad(43)$ & $663(26)$ & $683(42)$ & $838(46)$ & $113.8(45)$ & $143.8(43)$ \\
\hline$t$ & 0.32 & 274 & 1.55 & 321 & 018 & 0.10 \\
\hline$p$ & & $<001$ & & $<0002$ & & \\
\hline \multicolumn{7}{|l|}{ B. Females } \\
\hline Migraine & 410 & $60.8(18)$ & $72.8(32)$ & $90.5(32)$ & $113.3(31)$ & $1453(29)$ \\
\hline Control & $40.8 \quad(28)$ & $655(16)$ & $68.0(28)$ & $82.3(30)$ & $112.3(29)$ & $144.3(27)$ \\
\hline$t$ & 0.16 & 308 & 2.02 & 2.74 & 0.35 & 0.37 \\
\hline$p$ & & $<0005$ & $<0.05$ & $<0.01$ & & \\
\hline
\end{tabular}

* msec.

** No. of individuals

TABLE III

Analysis of amplitude averages for occipital components

\begin{tabular}{|c|c|c|c|c|c|c|}
\hline & OI & $\begin{array}{l}\text { Intermediate } \\
\text { cluster }\end{array}$ & OII & OIII & OIV & OV \\
\hline \multicolumn{7}{|c|}{$A$ Combined $(M$ and $F)$} \\
\hline Migraine & $2.9^{*}(50)^{* *}$ & $29(26)$ & $5.5(48)$ & $53(48)$ & $68(47)$ & $72(46)$ \\
\hline Control & 3.0 & $30(26)$ & $5.0(41)$ & $6.3(46)$ & $102(45)$ & $89(43)$ \\
\hline$t$ & 0.28 & 039 & 0.69 & 1.04 & 298 & 140 \\
\hline$p$ & & & & & $<0005$ & \\
\hline \multicolumn{7}{|l|}{$B$ Females } \\
\hline Migraine & $28 \quad(32)$ & $27(18)$ & $5.7(32)$ & $5.2(32)$ & $70(31)$ & $83(29)$ \\
\hline Control & $3.2(28)$ & $34(16)$ & $5.2(27)$ & $58(30)$ & $115(29)$ & $11.0(27)$ \\
\hline$t$ & 079 & 1.36 & 0.62 & 054 & 2.98 & 170 \\
\hline$p$ & & & & & $<0005$ & \\
\hline
\end{tabular}

$* \mu \mathrm{V}$.

** No of individuals

given in Table II When the male and female subgroups were combined, the latency of the intermediate cluster in patients with migraine was significantly shorter than in the controls. The migraine group also had a significantly longer latency of OIII. When female patients with migraine were compared with female controls, the intermediate cluster and OIII were again significantly different. Also, the latency of OII was slightly but significantly longer in patients with 
migraine than in controls. No differences, significant beyond the 0.05 level of confidence, were noted when male patients were compared with male controls.

Table III gives average amplitudes for the occipital waves The only difference noted was that the amplitude of OIV was significantly smaller in patients with migraine. This was present for male and female populations combined and for female patients alone. Again, no significant differences were detected between the male groups.

TABLE IV

Pupıl sizes (1n mm) for control and patient samples

\begin{tabular}{lccccc}
\hline & \multicolumn{2}{c}{ Pre-test } & & \multicolumn{2}{c}{ Post-test } \\
\cline { 2 - 3 } \cline { 5 - 6 } & Range & Average & & Range & Average \\
\hline Migraine & $20-5$ & 36 & $20-5$ & 34 \\
Control & $25-7$ & 47 & $2.5-7$ & 42 \\
$p$ & & $<0.001$ & & $<0001$ \\
\hline
\end{tabular}

Comparison of pupil sizes revealed that the patients with migrame had smaller pupıls, on the average, than subjects from the normal population (Table IV). Correlations between pupil size and each of the significant latency and amplitude values were not significant except for a correlation with the amplitude of OIV in the control group with both pre- and post-test data ( $p$ $<0.02$ and $<005$ ). Further analysis indicated, with pupil size held constant by covariance analysis. that a significant $(p<0.05)$ difference still existed between the mean amplitude of OIV in the migraine and control populations Covarlance analysis was possible only for the post-test pupil size values, the difference between regression coefficients being significant for pre-test data.

Records obtained on three patients, both during a migraine headache and during the headache-free interval, revealed no appreciable differences in the restıng EEG or photically evoked patterns No records were obtamed during the period of the aura.

The evoked responses of six patients who had field defects as part of their auras, but who were asymptomatic (headache-free) at the time of the examination, did not show significant differences from the group as a whole. The evoked responses of the two patients with photoconvulsive responses to rhythmic stımulatıon did not differ appreciably from the remainder of the group

Drugs did not appear to be of importance in altering the evoked response. Sixteen patients with migraine had taken medication within $48 \mathrm{~h}$ of the EEG Among both males and females four received Bellergal, two had taken Sansert, and one recerved Caffergot The remaining nine were females, the majority of whom were taking Enovid; one Librium; another Dexamyl

\section{DISCUSSION}

Routine EEGs in the patients with migraine, obtained during the headache-free interval, were abnormal in $22^{\circ}{ }_{0}$ of the cases. This is within the lower portion of the range of mcidences of abnormal records as reported by various investigations, and less than half the $59^{\circ}{ }_{0}$ found by Dow and Whitty (1947) who studied a similar number of patients Such differences may be due to variation of the patıent sample. diagnostic problems in some patıents, and dissımilarıty in criteria of abnormality

If the vertex sharp wave is a non-specific response related to the startle reaction (see Gastaut 1954, Larsson 1956), it would seem that, during the headache-free interval, the patient with migrame does not differ in startle responsiveness from the individual without migrame

A major (intermediate) subcomponent of OI, prominent in both groups, appeared slightly earlier in the sample of patients The fact that it was not significant for the male group may indicate that some sex-related factor is influencing this finding. The age factor may also be important in evaluating this deflection. The intermediate component, although present in a rudimentary fashion in previous control data (Koo1 and Bagch1 1964a), was not one of the three most prominent waves as frequently as in this study However, the mean age of subjects in the previous group, consisting mostly of males, was 481 years as compared to 293 years for the present control subjects Mean latency of OIII was significantly longer in the total group with migraine and the female subsample but not in the male group. For females only, the mean latency of OII was slightly longer in the headache than in the control group.

Electroenceph clin Neurophy'stol., 1966, 21:23-27 
The hypothesis that migraine might be assoclated with an exaggerated cerebral response to light was not substantiated by the study. The only significant difference found in amplitude involved the OIV wave which was decreased in migrane, a finding present in both the total and female, but not male, populations.

The existence of significant findings in both latencies and amplitude in the female group and not in the male population reinforces the possibility of some sex factor being involved.

To our knowledge, the fact that patients with migraine, under conditions of controlled background light intensity, may have smaller pupıls than non-migrainous subjects, has not previously been reported. Small pupil size, by reducing the amount of light falling upon the retina, may conceivably affect the occipital evoked response in a systematic way. However, correlations between pupil size and the measures found to be significantly different for the two groups revealed that only the amplitude of OIV was significantly related to pupil size in the present normal sample In a previous analysis of a larger series of controls, ranging more widely in age, no significant correlations emerged between pupıl size and any parameter of the response; i.e., amplitudes and latencies of OI-OV (Kool and Bagchi 1964b).

\section{SUMMARY}

Visually evoked responses from the central and occipital areas were compared between 50 patients with migraine (during the headache-free period) and 46 control subjects. The findings suggest that migraine might be associated with altered cerebral responses to visual stımulation Of three occipital surface negative components studied, the second ("intermediate" cluster) tended to appear slightly earlier in the migrainous individuals whereas the third (OIII) appeared later. Average amplitude of the second major surface positive wave (OIV) was lower. These differences were significant for the total experimental population and the female subgroup. Latency of the OII component (surface positive) was longer for females with migraine, a finding not present for the total population. No significant differences emerged between male exper1mental and control groups Vertex responses were sımilar in migrainous and normal subjects The routine EEG was abnormal in eleven of 50 $(22 \%)$ patients

Average pupil size of the patients with migraine was significantly smaller than that of the controls.

The authors wish to express appreciation to Dr R N DeJong for review of the manuscript, Mr W Kohl who carried out most of the studies, and Miss E. B Schaeffer of the Rackham Statistical Research Laboratory for statistical calculations

\section{REFERENCES}

Classification of headache $J$ Amer med Ass, 1962, 179. 717-718.

Dow, D J. and WhiтtY, C W. M Electroencephalographic changes in migraine, review of 51 cases Lancet, 1947, $u$ 52-54.

GastaUt, Y Negative spikes evoked at the vertex. Their psychophysiologic and pathologic significance Electroenceph. clin Neurophysiol., 1954, 6:161

Golla, F. L and Winter, A L Analysis of cerebral responses to flicker in patients complaining of episodic headache Electroenceph clin Neurophysiol, 1959, 11: 539-549.

KooI, $\mathrm{K}$ A. and BAGCHI, B. K Visual evoked responses in man. normative data. Ann NY Acad $S c l, 1964 a$, $112 \quad 254-269$.

KooI, K A. and BagCHI, B K. Observations on early components of the visual evoked response and occipıtal rhythms Electroenceph clin Neurophystol, 1964b, 17 638-643

Kool, K A., Guvener, A. M. and Bagchi, B K. Visual evoked responses in lesions of the higher optic pathways. Neurology (Minneap), 1965, 15: 841--854

LARSSON, L E The relation between the startle reaction and the non-specific EEG response to sudden stımulı with a discussion on the mechanism of arousal Electroenceph clin Neurophysiol, 1956, 8. 631--644

Smyth, V O G and Winter, A. L The EEG in migraine Electroenceph clin Neurophysiol, 1964, 16 194-202

Reference RICHEY, E T, KOOI, K. A and WAGGONER, R W. Visually evoked responses in migraine. Electroenceph. clin. Neurophystol, 1966, 21·23-27. 